\title{
The NF-kB p65 and p50 homodimer cooperate with IRF8 to activate iNOS transcription
}

\author{
Priscilla S. Simon ${ }^{1,3,4}$, Sarah K. Sharman 1,3, Chunwan Lu, ${ }^{1,4}$, Dafeng Yang ${ }^{1,4}$, Amy V. Paschall ${ }^{1,3,4}$,
} Sidhartha S. Tulachan ${ }^{2}$ and Kebin Liu ${ }^{1,3,4^{*}}$

\begin{abstract}
Background: Inducible nitric oxide synthase (iNOS) metabolizes L-arginine to produce nitric oxide (NO) which was originally identified in myeloid cells as a host defense mechanism against pathogens. Recent studies, however, have revealed that iNOS is often induced in tumor cells and myeloid cells in the tumor microenvironment. Compelling experimental data have shown that iNOS promotes tumor development in certain cellular context and suppresses tumor development in other cellular conditions. The molecular mechanisms underlying these contrasting functions of iNOS is unknown. Because iNOS is often induced by inflammatory signals, it is therefore likely that these contrasting functions of iNOS could be controlled by the inflammatory signaling pathways, which remains to be determined.
\end{abstract}

Methods: iNOS is expressed in colon carcinoma and myeloid cells in the tumor microenvironment. Colon carcinoma and myeloid cell lines were used to elucidate the molecular mechanisms underlying iNOS expression. Chromatin immunoprecipitation and electrophoretic mobility shift assay were used to determine the IFNY-activated pSTAT1 and NF-KB association with the chromatin DNA of the nos2 promoter.

Results: We show here that iNOS is dramatically up-regulated in inflammed human colon tissues and in human colon carcinoma as compared to normal colon tissue. iNOS is expressed in either the colon carcinoma cells or immune cells within the tumor microenvironment. On the molecular level, the proinflammatory IFNY and NF-KB signals induce iNOS expression in human colon cancer cells. We further demonstrate that NF-KB directly binds to the NOS2 promoter to regulate iNOS expression. Although neither the IFNy signaling pathway nor the NF-KB signaling pathway alone is sufficient to induce iNOS expression in myeloid cells, IFNY and NF-KB synergistically induce iNOS expression in myeloid cells. Furthermore, we determine that IFNy up-regulates IRF8 expression to augment NF-kB induction of iNOS expression. More interestingly, we observed that the p65/p65 and p50/p50 homodimers, not the canonical p65/p50 heterodimer, directly binds to the nos 2 promoter to regulate iNOS expression in myeloid cells.

Conclusions: IFNy-induced IRF8 acts in concert with NF-KB to regulate iNOS expression in both colon carcinoma and myeloid cells. In myeloid cells, the NF-kB complexes that bind to the nos 2 promoter are p65/p65 and p50/p50 homodimers.

Keywords: iNOS, NF-KB, IFNy, IRF8, pSTAT1, Colon cancer

\footnotetext{
* Correspondence: Kliu@gru.edu

'Department of Biochemistry and Molecular Biology, Medical College of Georgia, Georgia Regents University, Augusta, GA 30912, USA

${ }^{3}$ Cancer Center, Georgia Regents University, Augusta, GA 30912, USA

Full list of author information is available at the end of the article
} 


\section{Background}

Nitric Oxide Synthase (NOS) metabolizes L-arginine to form the intermediate $\mathrm{OH}$-L-arginine, which is then oxidized into nitric oxide (NO) and L-citrulline in eukaryotic cells. Inducible NOS (iNOS, also termed NOS2) is a type of NOS which was originally identified in myeloid cells. iNOS is induced in myeloid cells after activation by endotoxins or cytokines to generate $\mathrm{NO}$ that acts as a defense effector to suppress invading microorganisms or neoplastic tissue [1, 2]. However, it is now clear that iNOS is also present in numerous types of non-immune cells, including endothelial cells, fibroblasts, vascular smooth muscle cells, cardiac myocytes, and cancerous cells $[3,4]$.

Consistent with its function as a host defense agent, iNOS can protect certain host tissues from certain infectious diseases. Compelling experimental data indicate that iNOS is inducible in tumor cells and function as a tumor suppressor [3-9]. NO functions as a cytotoxic agent that can suppress cancer development [10-15]. However, overwhelming experimental data from both human cancer patients and mouse tumor models indicate that iNOS can also promote tumor development [16-25]. It is now clear that iNOS induction is a common phenomenon of chronic inflammation, and iNOS-produced NO acts as a key signaling molecule that promotes inflammationmediated spontaneous colon cancer development [18, 26]. One mechanism underlying iNOS function in tumor promotion might be its function in regulation of the tumorinitiating properties of cancer stem cells [27, 28].

Myeloid cells are often abundantly present in many solid tumors [29], and are another major site of iNOS expression $[8,9,30]$. Like in tumor cells, iNOS also exhibits contrasting functions in myeloid cells in the context of tumor development [18]. It has been shown that macrophages are required for phthisic rejection of intraocular tumors, and in vitro and in vivo inhibition of iNOS abolished macrophage-mediated killing of tumor cells and rejection of tumors [2, 8]. Furthermore, under hypoxic conditions, the induction of iNOS activity in myeloid cells is associated with a substantial increase in tumor cell toxicity [9]. However, recent studies suggest that iNOS expressed in myeloid cells also plays a key role in myeloid cellmediated immune suppression and tumor promotion [31-34]. Myeloid cells from colon carcinoma-bearing mice exhibit elevated iNOS and NO, which is associated with increased levels of nitration on STAT1, resulting in suppression of the anti-tumor immune response [30]. Therefore, iNOS expression occurs in both tumor cells and tumor-associated myeloid cells, and can act in concert to promote tumor development.

iNOS expression is induced by various inflammatory stimuli that activate distinct signaling pathways that converge to initiate expression of iNOS [35, 36]. One of the well-known iNOS inducers is NF-kB [37]. However, NF- $\mathrm{kB}$ has contrasting functions as well. NF- $\kappa B$ is a well-documented inflammatory factor that promotes inflammation-mediated colon cancer progression $[38,39]$. Overwhelming experimental data also demonstrate that NF- $\mathrm{kB}$ is an apoptosis promoter and tumor suppressor [40-44]. These contrasting functions of NF- $\mathrm{KB}$ are believed to be cellular context-dependent. The molecular mechanisms underlying NF- $\mathrm{KB}$ function in iNOS induction in colon cancer and myeloid cells are still not fully understood. IFN $\gamma$ is a key component of the host cancer immune surveillance system [45]. However, IFNY is also a two-edged sword and an inflammatory cytokine that regulates iNOS expression. Chronic IFNy signaling promotes spontaneous colon cancer development through an iNOS-dependent mechanism [26]. The fact that iNOS functions both to promote and suppress tumor development and that iNOS inducers IFN $\gamma$ and NF- $\mathrm{kB}$ also exhibit both tumor promotion and suppression functions raise the possibility that IFN $\gamma$ and NF-kB-mediated iNOS induction mechanisms dictate iNOS expression level and functionalities. However, the molecular mechanism underlying IFN $\gamma$ and NF- $\mathrm{kB}$ regulation of iNOS expression is still elusive.

We report here that iNOS is expressed in both human colon carcinoma cells and tumor-infiltrating immune cells. We determined that IFN $\gamma$ and NF-kB synergistically induce iNOS expression in both tumor cells and myeloid cells. Furthermore, IFN $\gamma$ up-regulates IRF8 expression that is essential for IFN $\gamma$ and NF- $\mathrm{kB}$ induction of iNOS expression. We determined that NF- $\mathrm{KB}$ functions through direct binding to the iNOS promoter to activate iNOS transcription. In myeloid cells, the p65/p65 and p50/p50 NF- $\mathrm{kB}$ homodimers directly bind to the iNOS promoter, thereby revealing an essential role of the p65/p65 and p50/p50 homodimers in NF-kB induction of iNOS.

\section{Methods}

\section{Cell lines and human tissue specimens}

The human colon carcinoma T84 cell lines and murine J774 myeloid cell lines were obtained from American Type Culture Collection (ATCC) (Manassas, VA). ATCC has characterized these cells by morphology, immunology, DNA fingerprinting, and cytogenetics. The CL-2 cell line was kindly provided by Dr. Keiko Ozato (National Institutes of Health, Bethesda, MD) [46]. De-identified human colon carcinoma specimens were obtained from the Cooperative Human Tissue Network and used with approval by The Georgia Regents University Human Assurance Committee (approval \# 730193-1).

\section{RT-PCR analysis}

Total RNA was isolated from cells using Trizol (Invitrogen, San Diego, CA) according to the manufacturer's 
Table 1 Oligo sequences

\begin{tabular}{|c|c|c|c|}
\hline Oligo Name & Use & Forward & Reverse \\
\hline hiNOS & RT-PCR & 5'- ACATCACCACACCCCCAACC -3' & 5'- GAAAGCAGGAAGCCAGCAGAC -3' \\
\hline hICSBP (IRF8) & RT-PCR & 5'-CCAGATTTTGAGGAAGTGACGGAC-3' & 5'-TGGGAGAATGCTGAATGGTGC-3' \\
\hline $\mathrm{h} \beta$-actin & RT-PCR & 5'- GGAACGGTGAAGGTGACAGCAG -3' & 5'- TGTGGACTTGGGAGAGGACTGG -3' \\
\hline hiNOS-ChIP1 & Chromatin immunoprecipitation & 5'- CCACAGGTCAAGAATGCCACAC -3' & 5'- AATGCCCCCACCCAAGAGCC -3' \\
\hline hiNOS-ChIP2 & Chromatin immunoprecipitation & 5'- ACTCCTAATCATCCCTCAAAACCC -3' & 5'- CATCTGCCACGAAGAGCAATG -3' \\
\hline hiNOS-ChIP3 & Chromatin immunoprecipitation & 5'- GGACTTGGGACCAGAAAGAGGTG -3' & 5'- GCCATCCAGAGAGTTGTIITTGC -3' \\
\hline hiNOS-ChIP4 & Chromatin immunoprecipitation & 5'- GGTCTCTTCCTGGTTTGACTGTCC -3' & 5'- TTCCAACACCTTCTCTCTGTAGGC -3' \\
\hline hiNOSNF-kB Probe & EMSA & 5'-AAAATTGTGGGAATITTCTGCCTAC-3' & 5'-GTAGGCAGAAAATTCCCACAATTTT-3' \\
\hline NFB WT Probe & EMSA & 5'-CGGGAATTCCC-3' & 5'-GGGAATTCCCG-3' \\
\hline miNOS & RT-PCR & 5'-CCAGAGGACCCAGAGACAAGC-3' & 5'-GGCAGCACATCAAAGCGGC-3' \\
\hline$m \beta$-actin & RT-PCR & 5'-CTGGCACCACACCTTCTACAATG-3' & 5'-GGGTCATCTITTCACGGTTGG-3' \\
\hline miNOSChIP1 & Chromatin immunoprecipitation & 5'-ATGGTGTCTTCTGCCTCGCAAG-3' & 5'-CCCCAGGATTCCACTGTTGAAC-3' \\
\hline miNOSChIP2 & Chromatin immunoprecipitation & 5'-AAAGGAGAAACAGCCACCAAGC-3' & 5'-AGCACCCACAACCCAAAGAAC-3' \\
\hline miNOSChIP3 & Chromatin immunoprecipitation & 5'-TCCATCCCCTGAGCAATGTG-3' & 5'-CCCCCCAAACCCAATACTTG-3' \\
\hline miNOSChIP4 & Chromatin immunoprecipitation & 5'-CACAGCCCATCCACTATTCTGC-3' & 5'-CCAGGACACATTCATCAGGAGG-3' \\
\hline miNOSChIP5 & Chromatin immunoprecipitation & 5'-ACTCAGGGTAGGGTCCAGTTCATC-3' & 5'-TATGTGGCTTCTCCTTGGCGAG-3' \\
\hline miNOSNF-kB Probe & EMSA & 5'-GCTAGGGGGATTTTCCCTCTCTC-3' & 5'-GAGAGAGGGAAAATCCCCCTAGC-3' \\
\hline
\end{tabular}

instructions, and used for cDNA synthesis using the MMLV reverse transcriptase (Promega, Madison, WI). The cDNA was then used as the template for PCR amplification. RT-PCR was conducted as previously described [47]. The sequences of primers are listed in Table 1.

\section{Immunoprecipitation and Western blotting analysis}

Western blotting analysis was performed as previously described [48]. The blot was probed with antibodies specific for iNOS (BD Biosciences), STAT1 (BD Biosciences), pSTAT1 (BD Biosciences), and $\beta$-actin (Sigma-Aldrich). Immunoprecipitation was done with anti-p65 and anti-
A

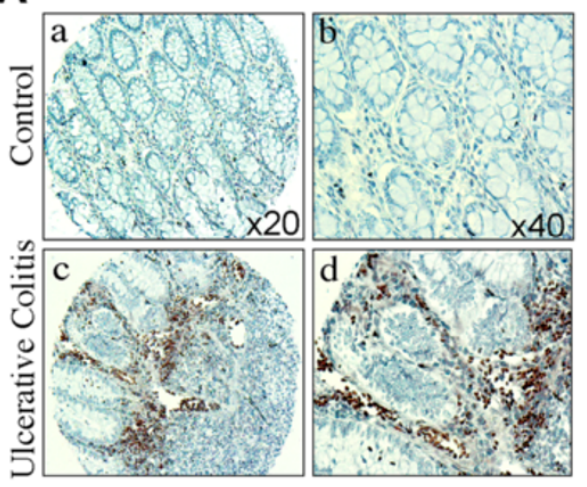

B
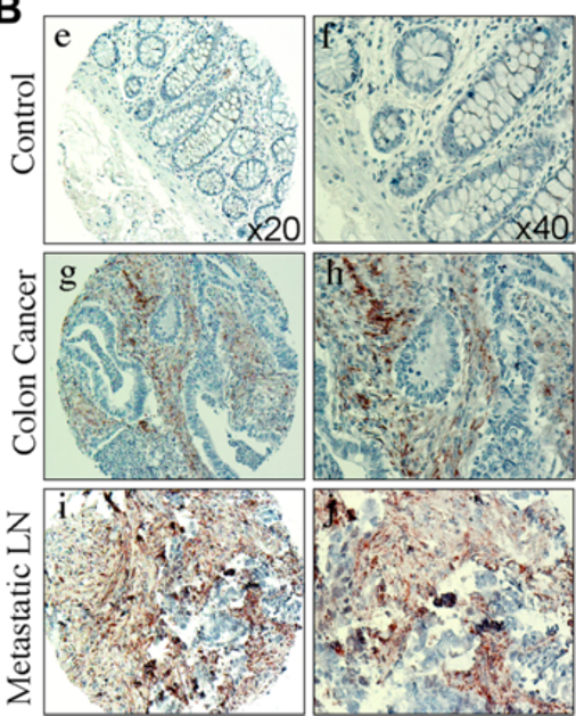

Fig. 1 iNOS protein profiles in human colon tissues. a Normal colon tissues $(a \& b)$ and colon tissues from human ulcerative colitis patients ( $c$ \& $d$ ) were stained with iNOS-specific antibody. Shown are images of representative results. Upregulation of iNOS expression was seen in inflammatory cells of ulcerative colitis $(c \& d)$. b Normal colon tissues $(e \& f)$, primary colon carcinoma tissues $(g \& h)$ and Metastatic Lymph Node (LN) (i \& $)$ ) were stained with iNOS-specific antibody. Shown are images of representative results. Normal colon tissues exhibit no detectable iNOS (e \& f). Upregulation of iNOS expression was seen in inflammatory cells of the primary tumor tissues $(g \& h)$ and Metastatic LN $(i \& j)$ 
p50 (Santa Cruz Biotech), as previously described $[49,50]$. The immunoprecipitated proteins were analyzed by Western blot analysis with anti-p65 (Santa Cruz Biotech).

\section{Cell treatment}

Cells were treated with IFNY (100 IU/ml, PeproTech), TNFa (100 IU/ml, R \& D System), and Lipopolysaccharide (LPS, $1 \mu \mathrm{g} / \mathrm{ml}$, Sigma-Aldrich) as indicated overnight. JakSTAT inhibitor Ruxolitinib (250 nM, LC Laboratories) was added to the cell culture $30 \mathrm{~min}$ before addition of IFN $\gamma$, TNF $\alpha$, or LPS.

\section{Immunohistochemistry}

Immunohistochemical staining was performed at the Georgia Pathology Service. iNOS-specific antibody was obtained from Santa Cruz Biotech.

\section{Chromatin immunoprecipitation (ChIP) assay}

ChIP assays were carried out using anti-p65 and anti-p50 antibodies (Santa Cruz Biotech) and protein A-agarose beads (Millipore) as previously described [48]. The human and mouse iNOS promoter DNA was detected by PCR using gene-specific primers (Table 1).

\section{Protein-DNA interaction assay}

DNA-protein interaction was determined by electrophoresis mobility shift assay (EMSA) as previously described [51]. Nuclear extracts were prepared as previously described [52]. The probe sequences are listed in Table 1.

\section{Gene silencing}

Tumor cells were transiently transfected with scramble and IRF8-specific siRNAs (Santa Cruz Biotech), respectively and analyzed for IRF8 and iNOS expression by RT-PCR.

\section{Gene overexpression}

Cells were electroporated with pcDNA 3.1 (vector control) or pcDNA.IkBa-AA (kindly provided by Dr. Michael Karin, University of California, San Diego). The cells were then cultured overnight and treated with IFNY and LPS for another $18 \mathrm{~h}$.

\section{Results}

\section{iNOS expression profiles in human colon tissues}

We made use of a human colorectal cancer tissue microarray (Cooperative Human Tissue Network) and stained for iNOS protein levels. Because colonic inflammation is a key cause of colon cancer, we focused our analysis on colon tissues from human ulcerative colitis patients and colon cancer patients. The normal human colon tissues exhibit no detectable iNOS protein level. In contrast,
iNOS protein level is high in colon tissues from ulcerative colitis patients (Fig. 1a). Human primary colon carcinoma tissues also exhibit high level of iNOS, but most of the iNOS-positive cells are non-tumor cells in the tumor microenvironment (Fig. 1b). However, the lymph node metastatic colon carcinoma cells exhibit high iNOS expression level (Fig. 1b). These observations indicate that iNOS

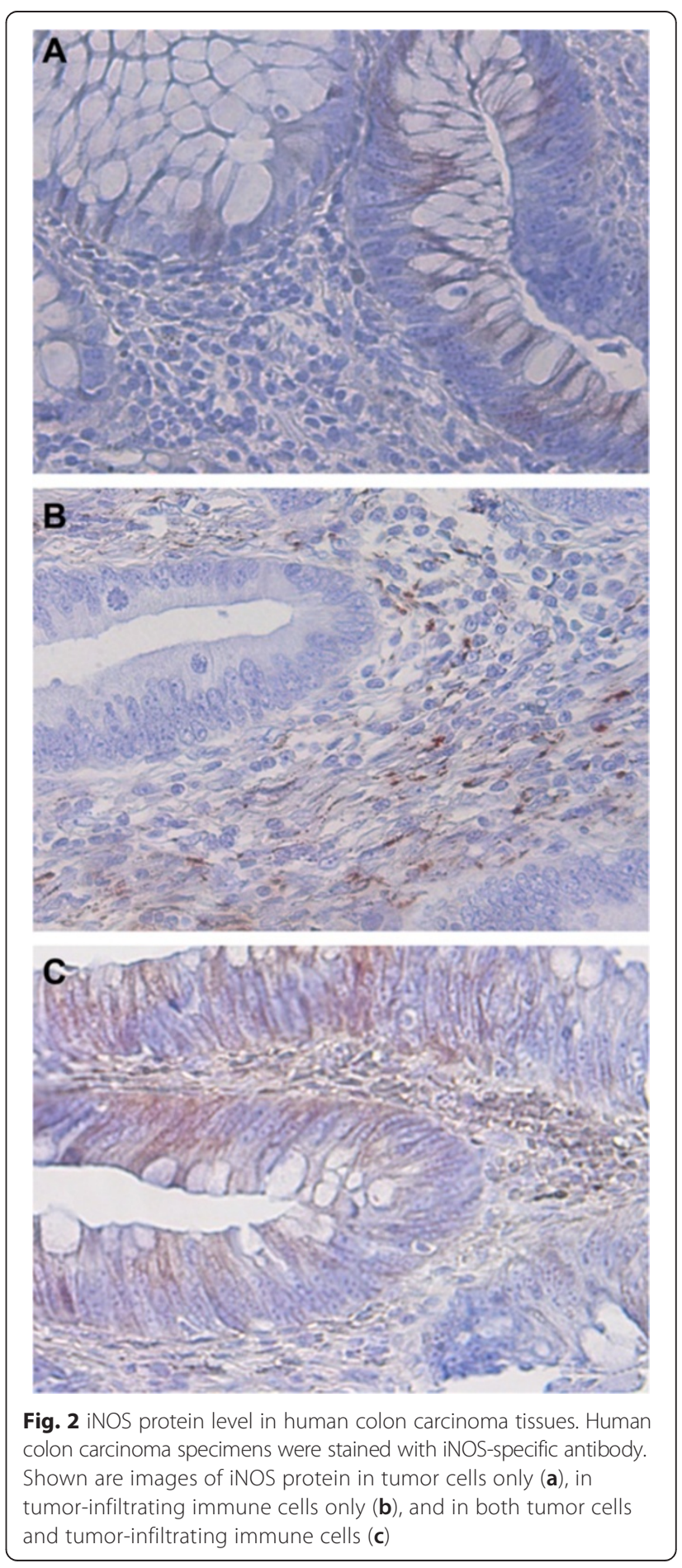


is up-regulated in inflammatory colon epithelial cells, colon carcinoma cells, and tumor-infiltrating immune cells.

\section{iNOS expression patterns in the human tumor microenvironment.}

Further analysis of the primary human colon carcinoma tissues revealed three types of iNOS expression patterns: 1) only tumor cells are iNOS-positive and no adjacent immune cells contain iNOS (Fig. 2a); 2) tumor cells exhibit undetectable iNOS, but adjacent immune cells express iNOS (Fig. 2b); and 3) both tumor cells and adjacent immune cells have detectable iNOS protein (Fig. 2c). These observations indicate that iNOS is expressed in both colon cancer cells and tumor-infiltrating immune cells under pathological conditions.

\section{IFN $Y$ and TNFa synergistically induce iNOS expression in} human colon carcinoma cells.

The IFN $\gamma$ and NF- $\mathrm{kB}$ signaling pathways have been shown to regulate iNOS expression in various types of cells [35, 36, 53-57]. To elucidate the molecular mechanisms underlying IFN $\gamma$ - and NF-KB-mediated iNOS expression in human colon carcinoma cells, human colon carcinoma T84 cells were treated with IFN $\gamma$, TNF $\alpha$, or both IFN $\gamma$ and TNF $\alpha$, and then analyzed for iNOS expression. RT-PCR analysis revealed that, as expected, IFN $\gamma$ induced iNOS expression in T84 cells. TNF $\alpha$
A
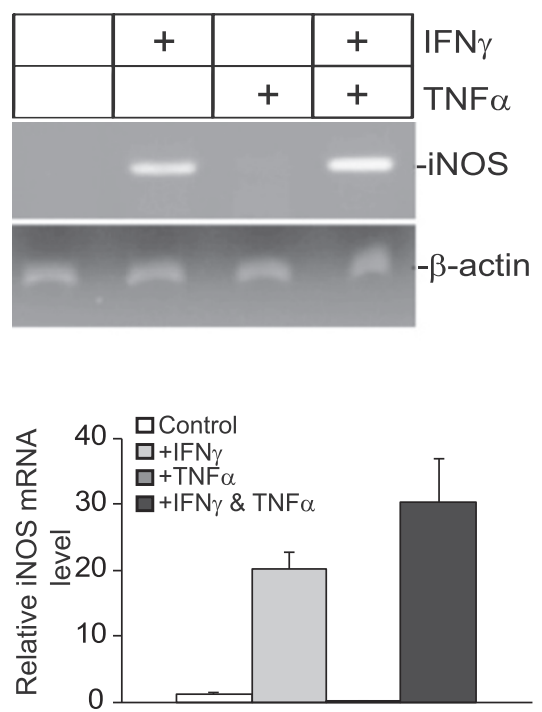

B

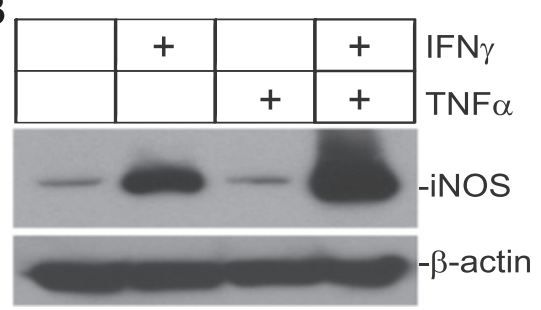

C

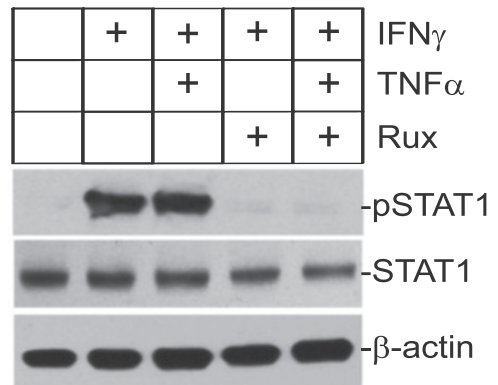

D

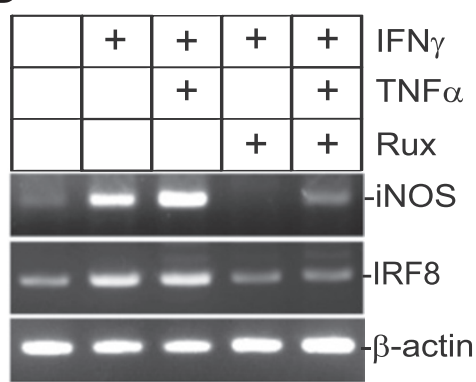

E

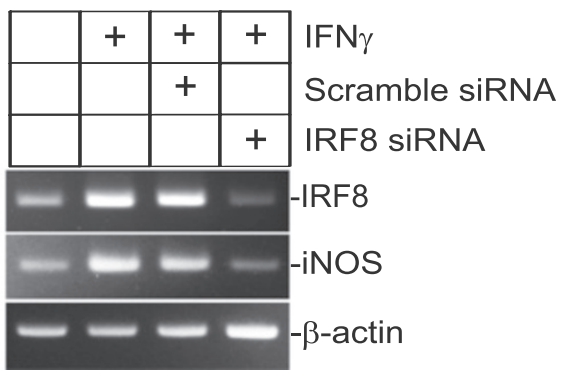

Fig. 3 IFNY and TNFa cooperatively induce iNOS expression in human colon carcinoma cells. a Tumor cells were treated with IFNy, TNFa, or both IFNy and TNFa for approximately $18 \mathrm{~h}$, and analyzed for iNOS expression by RT-PCR. $\beta$-actin was used as a normalization control. b Cells were treated as in A and then analyzed by Western blotting analysis of iNOS expression with $\beta$-action as an internal control. c Tumor cells were cultured in the presence of Ruxolitinib for $30 \mathrm{~min}$ and then treated with IFNY and TNFa as indicated for $18 \mathrm{~h}$. Total lysates were then prepared and analyzed for STAT1 and pSTAT1 levels by Western blotting analysis. $\mathbf{d}$ The cells were treated as in C and then analyzed by RT-PCR for iNOS expression. e The cells were transfected with either scramble siRNA or human IRF8-specific siRNA for $6 \mathrm{~h}$ and the cells were treated with IFNy for $18 \mathrm{~h}$. The cells were analyzed for IRF8 and iNOS expression by RT-PCR with $\beta$-actin as a normalization control 
alone did not induce iNOS expression (Fig. 3a), but TNF $\alpha$ dramatically increased IFN $\gamma$-induced iNOS expression (Fig. 3a). Consistent with iNOS mRNA expression patterns, iNOS protein levels were dramatically increased by IFN $\gamma$ but not by TNF $\alpha$ treatment (Fig. 3b). However, TNF $\alpha$ dramatically increased IFN $\gamma$-induced iNOS expression (Fig. 3b).

To determine that IFN $\gamma$ specifically induces iNOS expression, tumor cells were cultured in the presence of Ruxolitinib, a specific Jak/STAT inhibitor. As expected, Ruxolitinib blocked IFN $\gamma$ mediated STAT1 activation in human colon carcinoma cells (Fig. 3c). Consistent with inhibition of STAT1 activation, Ruxolitinib inhibited
IFNy induction of iNOS expression in the tumor cells (Fig. 3d). Interestingly, Ruxolitinib also diminished TNF $\alpha$ function in enhancing IFN $\gamma$ induction of iNOS expression (Fig. 3d), suggesting that both the IFNy signaling pathway and NF- $\mathrm{kB}$ are essential for iNOS induction. It has been previously reported that iNOS is regulated by IRF8 [58]. It is also known that IRF8 is regulated by IFN $\gamma$-activated pSTAT1 [59]. Therefore, we reason that IFN $\gamma$ activates pSTAT1 to activate IRF8 to upregulate iNOS. To test this hypothesis, we treated T84 cells with IFN $\gamma$ and TNF $\alpha$ in the presence of Ruxolitinib and analyzed IRF8 expression. Indeed, Ruxolitinib inhibited IRF8 expression. In order

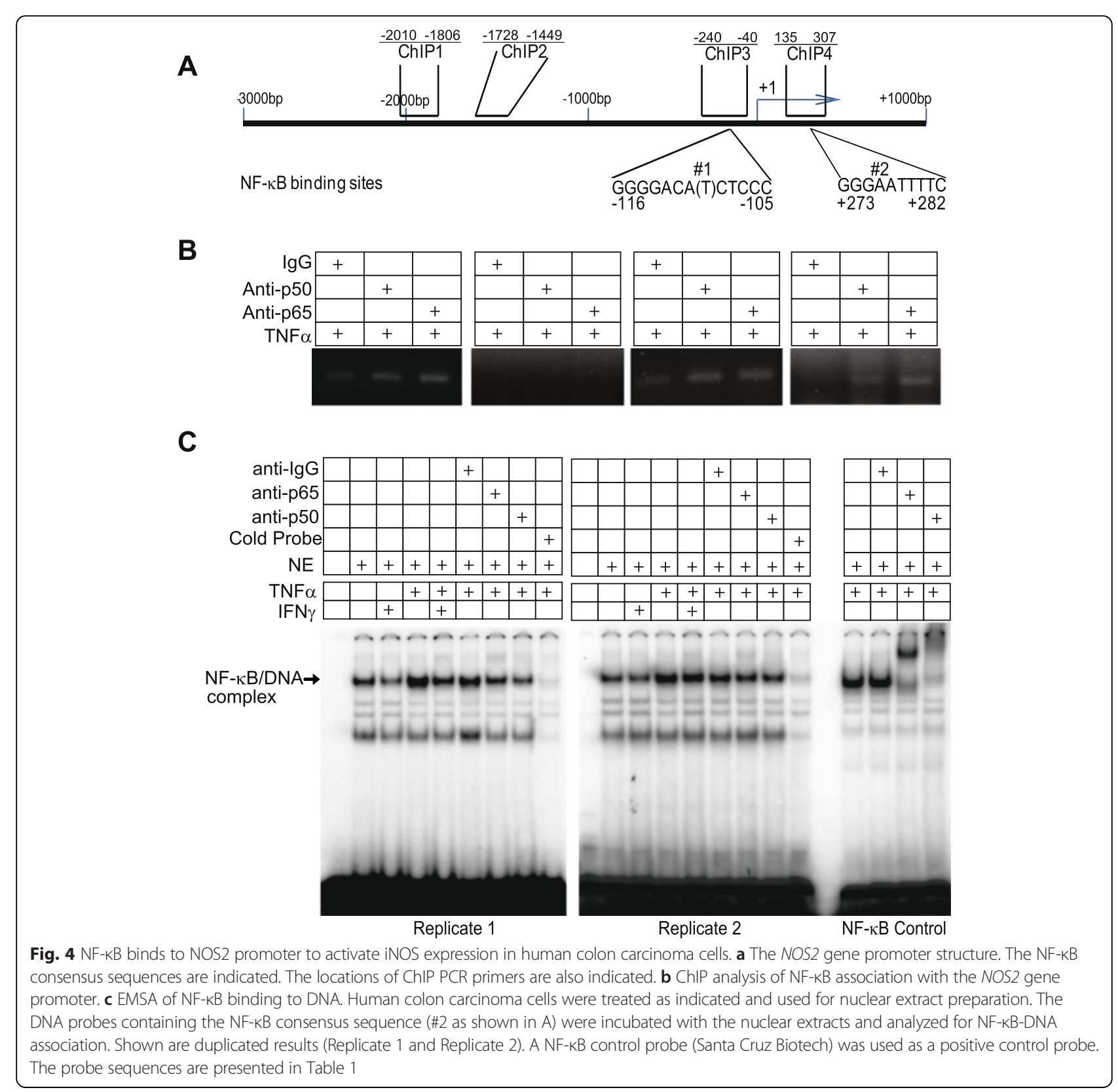


to validate the above observation that IFNy regulates iNOS expression through IRF8, a complimentary approach was used to determine the relationship between IRF8 and iNOS. IRF8 was silenced in T84 cells using an IRF8-specific siRNA. RT-PCR analysis indicate that silencing IRF8 expression diminished IFN $\gamma$ induced iNOS expression (Fig. 3e).

\section{NF-KB binds to the NOS2 promoter to regulate iNOS expression}

IFNy activates gene expression through Jak-dependent activation of STAT1 that binds to the target gene promoters to activate transcription [53], whereas TNF $\alpha$ activates NF$\kappa \mathrm{B}$ to directly activate gene transcription [35, 60]. The above results indicate that pSTAT1 indirectly regulates iNOS through IRF8 (Fig. 3e). Analysis of the human NOS2 gene promoter identified two putative NF-kB- binding consensus sequences (Fig. 4a). To determine whether TNF $\alpha$-activated NF- $\mathrm{kB}$ directly bind to the NOS2 promoter to activate iNOS transcription, NF- $\mathrm{kB}$-specific antibodies were used to determine the interactions of NF$\kappa \mathrm{B}$ with the NOS2 promoter chromatin. NF- $\mathrm{kB}$ association with the NOS2 promoter chromatin was detected in three regions of the NOS 2 promoter region in TNF $\alpha-$ treated tumor cells (Fig. 4b). To validate these findings, oligonucleotides containing the NF- $\mathrm{kB}$-binding consensus sequences of the NOS2 promoter (Fig. 4a) were synthesized. Oligonucleotides were annealed to generate doublestranded DNA probe (Table 1). The probes were labeled with ${ }^{32} \mathrm{P}$ and incubated with nuclear extracts prepared from untreated and treated cells. These DNA-protein interactions were analyzed by EMSA. Specific NF-kB/DNA interactions were detected, indicated that NF- $\mathrm{KB}$ directly regulates iNOS expression (Fig. 4c).
A

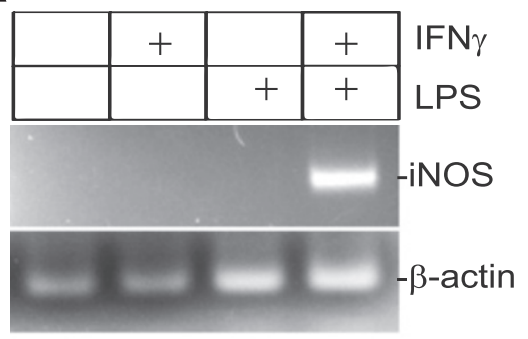

B

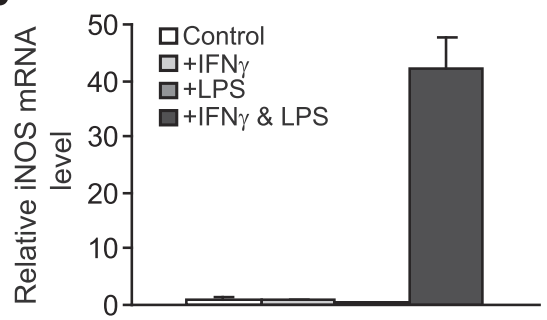

E

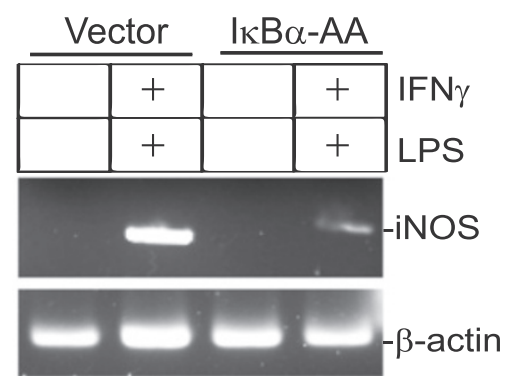

C

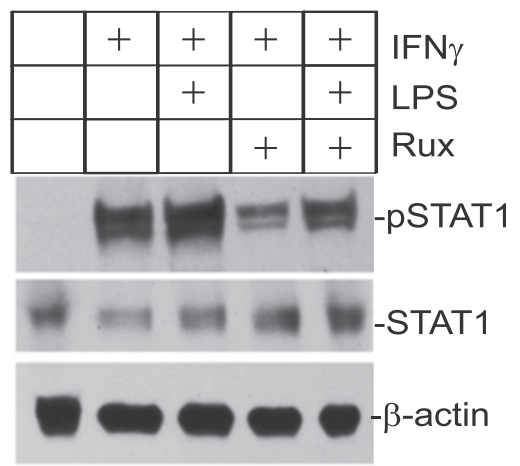

D

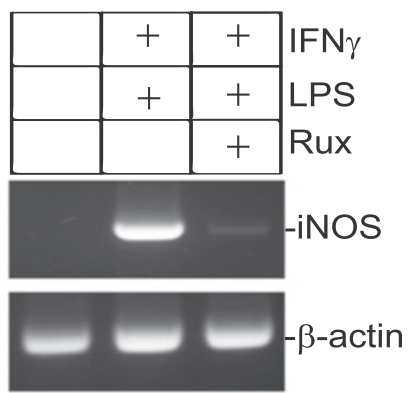

Fig. 5 IFNY and NF-KB induce iNOS expression in myeloid cells. a J774 cells were treated with IFNY, LPS, or both IFNY and LPS for approximately $18 \mathrm{~h}$, and analyzed for iNOS expression by RT-PCR. $\beta$-actin was used as a normalization control. $\mathbf{b}$ Cells were treated as in A and then analyzed by real time RT-PCR analysis of iNOS expression with $\beta$-action as an internal control. c J774 cells were cultured in the presence of Ruxolitinib for 30 min and then treated with IFNy and LPS as indicated for $18 \mathrm{~h}$. Total lysates were then prepared and analyzed for STAT1 and pSTAT1 levels by Western blotting analysis. d $\mathbf{J} 774$ cells were cultured in the presence of Ruxolitinib for 30 min and then treated with IFNy and LPS for 18 h. iNOS expression was then analyzed by RT-PCR. e $\mathbf{3 7 7 4}$ cells were transiently transfected with a control vector or a vector containing the dominant negative IKBa-AA mutant, respectively. Cells were treated with IFNy and LPS for approximately $18 \mathrm{~h}$, and then analyzed for iNOS expression 
pSTAT1 and NF-KB synergistically regulate iNOS expression in myeloid cells

To determine whether pSTAT1 and NF- $\mathrm{BB}$ also cooperate to up-regulate iNOS expression in myeloid cells, myeloid J774 cells were treated with IFN $\gamma$, LPS, or both IFN $\gamma$ and LPS. RT-PCR analysis revealed that neither IFN $\gamma$ nor LPS alone is sufficient to induce iNOS expression. However, combined IFNY and LPS dramatically induced iNOS expression in J774 cells (Fig. 5a \& b). To determine whether IFN $\gamma$ increases
iNOS expression specifically through the Jak-STAT signaling pathway, J774 cells were cultured in the presence of Ruxolitinib prior to IFNY and LPS treatment. As expected, Ruxolitinib inhibited IFN $\gamma$-induced STAT1 activation (Fig. 5c). It is also clear that Ruxolitinib specifically inhibits $\mathrm{NF}-\mathrm{\kappa B}$ and IFN $\gamma$-mediated iNOS expression induction (Fig. 5d). Next, we transi-

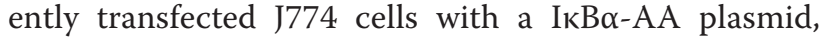
a dominant-negative mutant of $\mathrm{I} \kappa \mathrm{B} \alpha$ that blocks activation of the canonical NF-kB. RT-PCR analysis

A

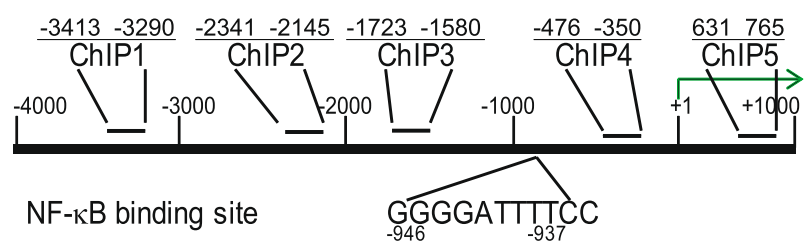

B

\begin{tabular}{|c|c|c|c|c|c|c|c|c|c|c|}
\hline \multicolumn{2}{|c|}{ ChIP1 } & \multicolumn{2}{|c|}{ ChIP2 } & \multicolumn{2}{|c|}{ ChIP3 } & \multicolumn{2}{|c|}{ ChIP4 } & \multicolumn{2}{|c|}{ ChIP5 } & \multirow{3}{*}{$\begin{array}{l}\text { IgG } \\
\text { anti-p65 }\end{array}$} \\
\hline+ & & + & & + & & + & & + & & \\
\hline & + & & + & & + & & + & & + & \\
\hline+ & + & + & + & + & + & + & + & + & + & LPS \\
\hline
\end{tabular}

C

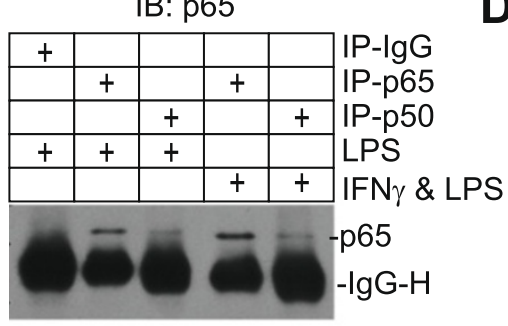

D

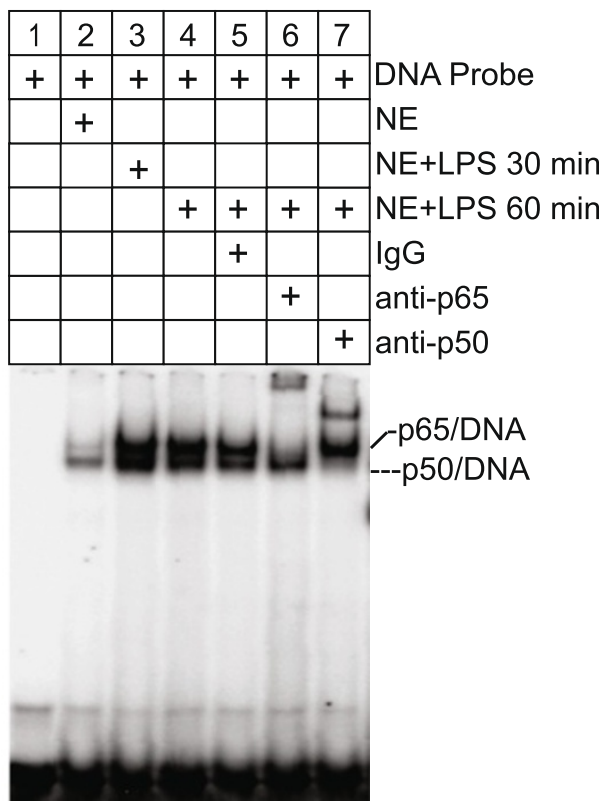

Fig. $6 \mathrm{NF}-\mathrm{kB}$ binds to nos 2 promoter to activate iNOS expression in myeloid cells. a The nos 2 gene promoter structure. The NF-kB consensus sequence is indicated. The locations of ChIP PCR primers are also indicated. $\mathbf{b}$ ChIP analysis of NF-KB association with the nos 2 gene promoter. $\mathbf{c}$ J774 cells were treated with LPS for approximately $1 \mathrm{~h}$. Nuclear extracts were prepared from the cells and used for immunoprecipitation (IP) with anti-p65 and anti-p50 antibodies, respectively. The IP was then analyzed by Western blotting analysis using p65-specific antibody. $\mathbf{d}$ EMSA of NF-kB binding to nos2 promoter DNA. $J 774$ cells were treated as indicated and used for nuclear extract preparation. The DNA probe containing the NF-KB consensus sequence as shown in A was incubated with the nuclear extracts and analyzed for NF-KB-DNA association using p65- and p50-specific antibodies 
revealed that blocking NF- $\mathrm{kB}$ activation inhibited IFN $\gamma$ and LPS-induced iNOS expression in J774 cells (Fig. 5e). These observations indicate that the IFNYactivated Jak-STAT signaling pathway acts in concert with NF-kB to regulate iNOS expression in myeloid cells.

\section{The NF-KB homodimers bind to the nos2 promoter to regulate iNOS expression}

Analysis of the mouse nos 2 gene promoter region identified a putative NF-kB-binding consensus sequence (Fig. 6a). ChIP was then used to determine whether NF- $\mathrm{kB}$ directly binds to the nos 2 promoter chromatin. NF- $\kappa B$ directly binds to multiple sites on the nos 2 promoter region in LPS-treated J774 cells (Fig. 6b).

$\mathrm{NF}-\mathrm{kB}$ contains 5 Rel subunits, and the most common NF- $\mathrm{kB}$ dimer is the $\mathrm{p} 65 / \mathrm{p} 50$ heterodimer. IP-Western blotting analysis revealed that indeed the p65/p50 NF- $\mathrm{kB}$ heterodimer exists in LPS-treated and both LPS and IFN $\gamma$ treated J774 cells (Fig. 6c). To validate that NF- $\mathrm{kB}$ exists as the $\mathrm{p} 65 / \mathrm{p} 50$ heterodimer at the nos 2 promoter region, we performed EMSA assays using p65- and p50-specific antibodies. The rationale is that if NF- $\mathrm{kB}$ binds to the NF- $\mathrm{kB}$ consensus sequence DNA of the nos 2 promoter, then p65/ p50-DNA complexes should be detected. Analysis of protein-DNA interactions with nuclear extracts from LPStreated J774 cells and the nos 2 promoter NF-kB consensus sequence-containing DNA probe identified two proteinDNA complexes (Fig. 6d). Surprisingly, p65- and p50specific antibody supershifts revealed that one of the DNA-protein complexes is the p65/p65-DNA complex and another is the p50/p50-DNA complex. No p65/p50-DNA complex was detected. Therefore, the p65/p65 and p50/p50 homodimers, not the p65/p50 heterodimer, bind to the nos 2 promoter region directly in myeloid cells.

\section{IFN $\gamma$ up-regulates IRF8 to enhance NF-KB-induced iNOS expression.}

Because pSTAT1 enhances iNOS expression through the intermediate factor IRF8 in human colon carcinoma cells (Fig. 3d \& e), we hypothesized that IFN $\gamma$ activates IRF8 to regulate iNOS expression in myeloid cells as well. To test this hypothesis, we first analyzed IRF8 expression. As expected, IFN $\gamma$ treatment dramatically increased IRF8 expression [59] (Fig. 7a), and LPS alone did not induce IRF8 expression (Fig. 7a). We then analyzed iNOS induction in IRF8-deficient cells. The rationale is that if IRF8 is essential for IFN $\gamma$ and NF-kB-mediated iNOS expression, then IRF8 deficiency should cause the loss of iNOS induction by IFN $\gamma$ and LPS. The IRF8 wild type J774 cells and the IRF8-deficient CL-2 cells [46] were treated with IFN $\gamma$ and LPS. RT-PCR analysis revealed that iNOS is induced in J774 but not in the IRF8-deficient CL-2 cells (Fig. 7b). Therefore, we, conclude that NF- $\mathrm{kB}$ enhances the IFN $\gamma$ -

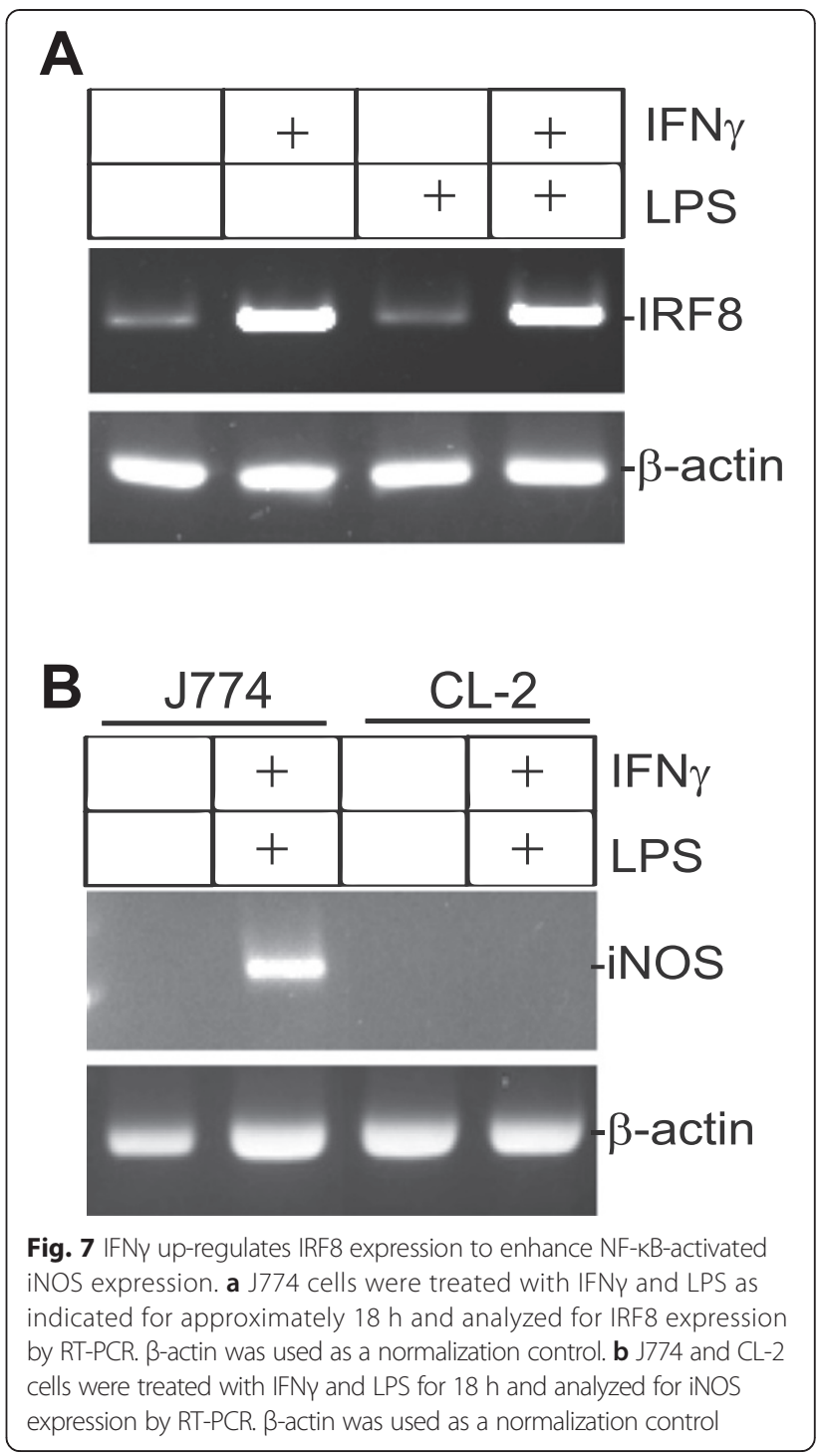

IRF8 axis-mediated induction of iNOS expression in myeloid cells.

\section{Discussion}

The expression of iNOS is induced by extracellular stimuli that activate distinct signaling pathways that converge to regulate iNOS transcription. Among the various extracellular stimuli, LPS, TNF $\alpha$, and IFN $\gamma$ are the three most extensively studied iNOS inducers $[1,35,36,53,54,56,57,61,62]$. IFN $\gamma$ functions through activating the Jak-STAT signaling pathway, whereas LPS and TNF $\alpha$ induce NF- $\mathrm{kB}$ activation to activate iNOS transcription. We show here that iNOS is expressed in both colon carcinoma cells and the tumorinfiltrating immune cells in the tumor microenvironment of human colon carcinoma tissues in vivo. Using the human colon carcinoma T84 cell line and the murine myeloid J774 cell line as in vitro model systems, we observed that 
both IFN $\gamma$-activated Jak-STAT and LPS/TNF $\alpha$-activated $\mathrm{NF}-\mathrm{kB}$ are essential for iNOS induction in both the tumor cells and the myeloid cells. Furthermore, the Jak-STAT signaling pathway and NF-kB synergistically activate iNOS transcription. Strikingly, although LPS induces the canonical p65/p50 heterodimer activation and nuclear translocation (Fig. 6c), no p65/p50-iNOS promoter DNA interactions are detected in myeloid cells. Instead, we observed that the p65/p65 and p50/p50 homodimers bind to the iNOS promoter (Fig. 6d). Our data thus reveal a novel finding that the NF- $\mathrm{kB}$ p65/p65 and p50/p50 homodimers, not the canonical $\mathrm{p} 65 / \mathrm{p} 50$ heterodimers, directly bind to the NF- $\mathrm{kB}$ consensus sequence element at the nos 2 promoter in myeloid cells.

The transcriptional regulation of iNOS has been the subject of extensive studies due to its diverse mechanisms of regulation. IFN $\gamma$ is a potent inducer of iNOS in various types of cells. Although IFNY can activate STAT1 that directly binds to gene promoter DNA to regulate IFN $\gamma$ target gene transcription, pSTAT1 often regulates IFNY target gene expression through activating transcription of IFN regulatory factors, including IRF8. IRF8 is a transcription factor that has been shown to regulate iNOS expression [57]. Indeed, IRF8 is dramatically up-regulated by IFNY in myeloid J774 cells, and loss of IRF8 expression abolished IFNY function in iNOS induction. Therefore, we conclude that IFNY induces IRF8 expression to regulate iNOS expression.

For NF-kB-mediated iNOS transcription activation, previous studies have identified several NF-kB-binding consensus sequence elements in both the human and mouse iNOS gene promoter regions [63]. We identified three NF-kB-binding sites in the iNOS promoter region in

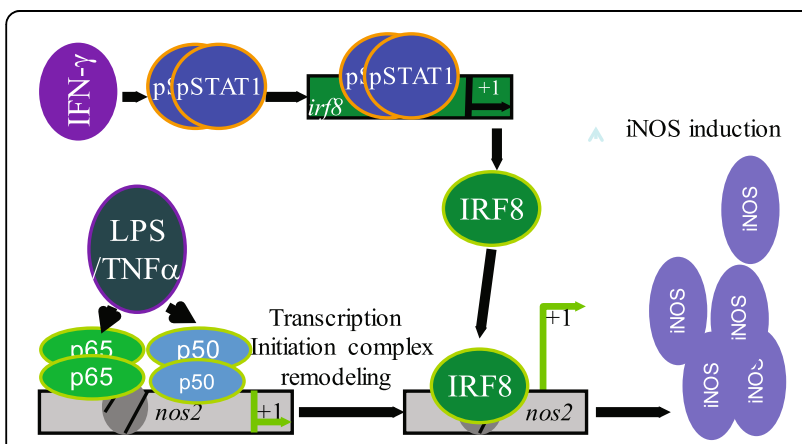

Fig. 8 Model of IFNy and NF-kB action in induction of iNOS expression in myeloid cells. IFNy and NF-kB induces iNOS expression in tumor cells and myeloid cells. Both IFNY-activated PSTAT1 and NF-KB are essential for the induction of iNOS. However, IFNy-activated PSTAT1 does not directly bind to the nos2 gene promoter. Instead, it activates IRF8 to regulate iNOS transcription. On the other hand, NF-KB directly binds to the nos2 gene promoter to activate iNOS transcription and it is the p65/p65 and p50/p50 NF-kB homodimers, not the canonical p65/p50 heterodimer, that bind to the nos 2 promoter region to activate iNOS transcription in myeloid cells human colon carcinoma cells and one in mouse myeloid cells. We further demonstrated that NF- $\mathrm{kB}$ directly binds to the NF-kB-binding consensus sequences in the iNOS gene promoter regions. Therefore, unlike IFN $\gamma$-activated pSTAT1, NF-kB directly binds to the iNOS promoter region to activate iNOS gene transcription in both human colon carcinoma and murine myeloid cells.

\section{Conclusions}

Our results provide a novel insight into the molecular mechanisms underlying transcription activation of iNOS gene by IFN $\gamma$ and NF-kB. IFN $\gamma$ and NF-kB induces iNOS expression in tumor cells and myeloid cells. Both IFN $\gamma$ activated pSTAT1 and NF- $\mathrm{kB}$ are essential for the synergistic induction of iNOS. However, IFN $\gamma$-activated pSTAT1 does not directly bind to the iNOS gene promoter. Instead, it activates IRF8 to regulate iNOS transcription. On the other hand, NF- $\mathrm{kB}$ directly binds to the iNOS gene promoter to activate iNOS transcription. It is the p65/p65 and p50/p50 NF-kB homodimers, not the canonical p65/p50 heterodimer, that bind to the iNOS promoter region to activate iNOS gene transcription in myeloid cells (Fig. 8).

\section{Competing interests}

The authors declare that they have no competing interests.

\section{Authors' contributions}

Concept and design: KL. Development of methodology: PSS, SKS, AVP, DY, SST, and KL. Acquisition of data: PSS, SKS, CL and DY. Analysis and interpretation of data: PSS, SKS, and KL. Writing and review of manuscript: PSS and KL. All authors have read and approved the manuscript.

\section{Acknowledgement}

We thank Ms. Kimya Jones at Georgia Pathology Service for excellent technical assistant in immunohistochemical staining of human tissues.

\section{Author details}

${ }^{1}$ Department of Biochemistry and Molecular Biology, Medical College of Georgia, Georgia Regents University, Augusta, GA 30912, USA. Medicine, Medical College of Georgia, Georgia Regents University, Augusta, GA 30912, USA. ${ }^{3}$ Cancer Center, Georgia Regents University, Augusta, GA 30912, USA. ${ }^{4}$ Charlie Norwood VA Medical Center, Augusta, GA 30904, USA.

Received: 22 April 2015 Accepted: 16 October 2015

Published online: 23 October 2015

\section{References}

1. Mishra BB, Rathinam VA, Martens GW, Martinot AJ, Kornfeld H, Fitzgerald KA, et al. Nitric oxide controls the immunopathology of tuberculosis by inhibiting NLRP3 inflammasome-dependent processing of IL-1beta. Nat Immunol. 2013;14:52-60.

2. Nascimento FR, Gomes EA, Russo M, Lepique AP. Interferon regulatory factor (IRF)-1 is a master regulator of the cross talk between macrophages and L929 fibrosarcoma cells for nitric oxide dependent tumoricidal activity. PLoS One. 2015;10:e0117782.

3. Crowell JA, Steele VE, Sigman CC, Fay JR. Is inducible nitric oxide synthase a target for chemoprevention? Mol Cancer Ther. 2003;2:815-23.

4. Fukumura D, Kashiwagi S, Jain RK. The role of nitric oxide in tumour progression. Nat Rev Cancer. 2006;6:521-34.

5. Kotamraju S, Williams CL, Kalyanaraman B. Statin-induced breast cancer cell death: role of inducible nitric oxide and arginase-dependent pathways. Cancer Res. 2007;67:7386-94.

6. Cook T, Wang Z, Alber S, Liu K, Watkins SC, Vodovotz Y, et al. Nitric oxide and ionizing radiation synergistically promote apoptosis and 
growth inhibition of cancer by activating p53. Cancer Res. 2004;64:8015-21.

7. Ramasamy K, Dwyer-Nield LD, Serkova NJ, Hasebroock KM, Tyagi A, Raina K, et al. Silibinin prevents lung tumorigenesis in wild-type but not in iNOS-/mice: potential of real-time micro-CT in lung cancer chemoprevention studies. Clin Cancer Res. 2011;17:753-61.

8. Coursey TG, Chen PW, Niederkorn JY. Abrogating TNF-alpha expression prevents bystander destruction of normal tissues during iNOS-mediated elimination of intraocular tumors. Cancer Res. 2011;71:2445-54.

9. Mehibel M, Singh S, Chinje EC, Cowen RL, Stratford IJ. Effects of cytokine-induced macrophages on the response of tumor cells to banoxantrone (AQ4N). Mol Cancer Ther. 2009;8:1261-9.

10. Liu Q, Chan ST, Mahendran R. Nitric oxide induces cyclooxygenase expression and inhibits cell growth in colon cancer cell lines. Carcinogenesis. 2003;24:637-42.

11. Moochhala S, Chhatwal VJ, Chan ST, Ngoi SS, Chia YW, Rauff A. Nitric oxide synthase activity and expression in human colorectal cancer. Carcinogenesis. 1996;17:1171-4.

12. Hao XP, Pretlow TG, Rao JS, Pretlow TP. Inducible nitric oxide synthase (iNOS) is expressed similarly in multiple aberrant crypt foci and colorectal tumors from the same patients. Cancer Res. 2001;61:419-22.

13. Scott DJ, Hull MA, Cartwright EJ, Lam WK, Tisbury A, Poulsom R, et al. Lack of inducible nitric oxide synthase promotes intestinal tumorigenesis in the Apc(Min/+) mouse. Gastroenterology. 2001;121:889-99.

14. Hussain SP, Trivers GE, Hofseth LJ, He P, Shaikh I, Mechanic LE, et al. Nitric oxide, a mediator of inflammation, suppresses tumorigenesis. Cancer Res. 2004;64:6849-53.

15. De Boo S, Kopecka J, Brusa D, Gazzano E, Matera L, Ghigo D, et al. iNOS activity is necessary for the cytotoxic and immunogenic effects of doxorubicin in human colon cancer cells. Mol Cancer. 2009;8:108.

16. Cianchi F, Cortesini C, Fantappie O, Messerini L, Schiavone N, Vannacci A, et al. Inducible nitric oxide synthase expression in human colorectal cancer: correlation with tumor angiogenesis. Am J Pathol. 2003;162:793-801.

17. Gochman E, Mahajna J, Shenzer P, Dahan A, Blatt A, Elyakim R, et al. The expression of iNOS and nitrotyrosine in colitis and colon cancer in humans. Acta Histochem. 2012;114:827-35.

18. Erdman SE, Rao VP, Poutahidis T, Rogers AB, Taylor $C L$, Jackson EA, et al. Nitric oxide and TNF-alpha trigger colonic inflammation and carcinogenesis in Helicobacter hepaticus-infected, Rag2-deficient mice. Proc Natl Acad Sci U S A. 2009;106:1027-32

19. Sikora AG, Gelbard A, Davies MA, Sano D, Ekmekcioglu S, Kwon J, et al. Targeted inhibition of inducible nitric oxide synthase inhibits growth of human melanoma in vivo and synergizes with chemotherapy. Clin Cancer Res. 2010;16:1834-44.

20. Engels K, Knauer SK, Loibl S, Fetz V, Harter P, Schweitzer A, et al. NO signaling confers cytoprotectivity through the survivin network in ovarian carcinomas. Cancer Res. 2008;68:5159-66.

21. Cianchi F, Cortesini C, Fantappie O, Messerini L, Sardi I, Lasagna N, et al. Cyclooxygenase-2 activation mediates the proangiogenic effect of nitric oxide in colorectal cancer. Clin Cancer Res. 2004;10:2694-704.

22. Ahn B, Ohshima H. Suppression of intestinal polyposis in $\mathrm{Apc}(\mathrm{Min} /+)$ mice by inhibiting nitric oxide production. Cancer Res. 2001;61:8357-60.

23. Nam KT, Oh SY, Ahn B, Kim YB, Jang DD, Yang KH, et al. Decreased Helicobacter pylori associated gastric carcinogenesis in mice lacking inducible nitric oxide synthase. Gut. 2004:53:1250-5.

24. Lopez-Rivera E, Jayaraman P, Parikh F, Davies MA, Ekmekcioglu S, Izadmehr S, et al. Inducible nitric oxide synthase drives MTOR pathway activation and proliferation of human melanoma by reversible nitrosylation of TSC2. Cancer Res. 2014;74:1067-78.

25. Cheng H, Wang L, Mollica M, Re AT, Wu S, Zuo L. Nitric oxide in cancer metastasis. Cancer Lett. 2014;353:1-7.

26. Hanada T, Kobayashi T, Chinen T, Saeki K, Takaki H, Koga K, et al. IFNgamma-dependent, spontaneous development of colorectal carcinomas in SOCS1-deficient mice. J Exp Med. 2006;203:1391-7.

27. Ausiliatrice Puglisi M, Cenciarelli C, Tesori V, Cappellari M, Martini M, Di Francesco AM, et al. High nitric oxide production, secondary to inducible-nitric oxide synthase expression, is essential for regulation of the tumour-initiating properties of colon cancer stem cells. J Pathol. 2015.

28. Granados-Principal S, Liu Y, Guevara ML, Blanco E, Choi DS, Qian W, et al. Inhibition of iNOS as a novel effective targeted therapy against triple-negative breast cancer. Breast Cancer Res. 2015;17:25.
29. Gabrilovich DI, Ostrand-Rosenberg S, Bronte V. Coordinated regulation of myeloid cells by tumours. Nat Rev Immunol. 2012;12:253-68.

30. Mundy-Bosse BL, Lesinski GB, Jaime-Ramirez AC, Benninger K, Khan M, Kuppusamy $P$, et al. Myeloid-derived suppressor cell inhibition of the IFN response in tumor-bearing mice. Cancer Res. 2011;71:5101-10.

31. Ito $H$, Ando T, Ogiso $H$, Arioka $Y$, Seishima M. Inhibition of induced nitric oxide synthase enhances the anti-tumor effects on cancer immunotherapy using TLR7 agonist in mice. Cancer Immunol Immunother. 2015;64:429-36.

32. Dufait I, Schwarze JK, Liechtenstein T, Leonard W, Jiang H, Escors D, et al. Ex vivo generation of myeloid-derived suppressor cells that model the tumor immunosuppressive environment in colorectal cancer. Oncotarget. 2015.

33. Lu G, Zhang R, Geng S, Peng L, Jayaraman P, Chen C, et al. Myeloid cell-derived inducible nitric oxide synthase suppresses M1 macrophage polarization. Nat Commun. 2015;6:6676.

34. Jayaraman P, Alfarano MG, Svider PF, Parikh F, Lu G, Kidwai S, et al. iNOS expression in CD4+ T cells limits Treg induction by repressing TGFbeta1: combined iNOS inhibition and Treg depletion unmask endogenous antitumor immunity. Clin Cancer Res. 2014;20:6439-51.

35. Hatano E, Bennett BL, Manning AM, Qian T, Lemasters JJ, Brenner DA. NF-kappaB stimulates inducible nitric oxide synthase to protect mouse hepatocytes from TNF-alpha- and Fas-mediated apoptosis. Gastroenterology. 2001;120:1251-62.

36. Thurston RD, Larmonier CB, Majewski PM, Ramalingam R, Midura-Kiela M, Laubitz D, et al. Tumor necrosis factor and interferon-gamma downregulate Klotho in mice with colitis. Gastroenterology. 2010;138:1384-94. 1394 e1381-1382.

37. Davis RL, Sanchez AC, Lindley DJ, Williams SC, Syapin PJ. Effects of mechanistically distinct NF-kB inhibitors on glial inducible nitric-oxide synthase expression. Nitric Oxide. 2005;12:200-9.

38. Chen F, Castranova V. Nuclear factor-kappaB, an unappreciated tumor suppressor. Cancer Res. 2007;67:11093-8.

39. Greten FR, Eckmann L, Greten TF, Park JM, Li ZW, Egan L, et al. IKKbeta links inflammation and tumorigenesis in a mouse model of colitis-associated cancer. Cell. 2004;118:285-96.

40. Liu F, Bardhan K, Yang D, Thangaraju M, Ganapathy V, Waller JL, et al. NF-kappaB Directly Regulates Fas Transcription to Modulate Fas-mediated Apoptosis and Tumor Suppression. J Biol Chem. 2012;287:25530-40.

41. Chien Y, Scuoppo C, Wang X, Fang X, Balgley B, Bolden JE, et al. Control of the senescence-associated secretory phenotype by NF-\{kappa\}B promotes senescence and enhances chemosensitivity. Genes Dev. 2011;25:2125-36.

42. Jennewein C, Karl S, Baumann B, Micheau O, Debatin KM, Fulda S. Identification of a novel pro-apoptotic role of NF-kappaB in the regulation of TRAIL- and CD95-mediated apoptosis of glioblastoma cells. Oncogene. 2012;31:1468-74.

43. Karl S, Pritschow Y, Volcic M, Hacker S, Baumann B, Wiesmuller L, et al. Identification of a novel pro-apopotic function of NF-kappaB in the DNA damage response. J Cell Mol Med. 2009;13:4239-56.

44. Varfolomeev E, Blankenship JW, Wayson SM, Fedorova AV, Kayagaki N, Garg P, et al. IAP antagonists induce autoubiquitination of C-IAPS, NF-kappaB activation, and TNFalpha-dependent apoptosis. Cell. 2007;131:669-81.

45. Shankaran V, Ikeda H, Bruce AT, White JM, Swanson PE, Old L, et al. IFNgamma and lymphocytes prevent primary tumour development and shape tumour immunogenicity. Nature. 2001;410:1107-11.

46. Tamura T, Thotakura P, Tanaka TS, Ko MS, Ozato K. Identification of target genes and a unique cis element regulated by IRF-8 in developing macrophages. Blood. 2005;106:1938-47.

47. Yang J, Hu X, Zimmerman M, Torres CM, Yang D, Smith SB, et al. Cutting edge: IRF8 regulates Bax transcription in vivo in primary myeloid cells. J Immunol. 2011;187:4426-30.

48. Zimmerman M, Yang D, Hu X, Liu F, Singh N, Browning D, et al. IFN- $\gamma$ Upregulates Survivin and Ifi202 Expression to Induce Survival and Proliferation of Tumor-Specific T Cells. PLoS One. 2010;5:e14076.

49. Zimmerman MA, Rahman NT, Yang D, Lahat G, Lazar AJ, Pollock RE, et al. Unphosphorylated STAT1 promotes sarcoma development through repressing expression of Fas and bad and conferring apoptotic resistance. Cancer Res. 2012;72:4724-32.

50. Zimmerman MA, Singh N, Martin PM, Thangaraju M, Ganapathy V, Waller JL, et al. Butyrate suppresses colonic inflammation through HDAC1-dependent Fas upregulation and Fas-mediated apoptosis of T cells. Am J Physiol Gastrointest Liver Physiol. 2012;302:G1405-15. 
51. Hu X, Yang D, Zimmerman M, Liu F, Yang J, Kannan S, et al. IRF8 regulates acid ceramidase expression to mediate apoptosis and suppresses myelogeneous leukemia. Cancer Res. 2011;71:2882-91.

52. Bardhan K, Paschall AV, Yang D, Chen MR, Simon PS, Bhutia YD, et al. IFNgamma induces DNA methylation-silenced GPR109A expression via pSTAT1/p300 and H3K18 acetylation in colon cancer. Cancer Immunol Res. 2015:3:795-805.

53. Schmidt N, Pautz A, Art J, Rauschkolb P, Jung M, Erkel G, et al. Transcriptional and post-transcriptional regulation of iNOS expression in human chondrocytes. Biochem Pharmacol. 2010;79:722-32.

54. Altamirano F, Lopez JR, Henriquez C, Molinski T, Allen PD, Jaimovich E. Increased resting intracellular calcium modulates NF-kappaB-dependent inducible nitric-oxide synthase gene expression in dystrophic mdx skeletal myotubes. J Biol Chem. 2012;287:20876-87.

55. Li K, Yao J, Shi L, Sawada N, Chi Y, Yan Q, et al. Reciprocal regulation between proinflammatory cytokine-induced inducible NO synthase (iNOS) and connexin43 in bladder smooth muscle cells. J Biol Chem. 2011;286:41552-62.

56. Stempelj M, Kedinger M, Augenlicht L, Klampfer L. Essential role of the JAK STAT1 signaling pathway in the expression of inducible nitric-oxide synthase in intestinal epithelial cells and its regulation by butyrate. J Biol Chem. 2007:282:9797-804

57. Xiong H, Zhu C, Li H, Chen F, Mayer L, Ozato K, et al. Complex formation of the interferon (IFN) consensus sequence-binding protein with IRF-1 is essential for murine macrophage IFN-gamma-induced iNOS gene expression. J Biol Chem. 2003;278:2271-7.

58. Paschall AV, Zhang R, Qi CF, Bardhan $K$, Peng L, Lu G, et al. IFN Regulatory Factor 8 Represses GM-CSF Expression in T Cells To Affect Myeloid Cell Lineage Differentiation. J Immunol. 2015;194:2369-79.

59. Kanno Y, Levi BZ, Tamura T, Ozato K. Immune cell-specific amplification of interferon signaling by the IRF-4/8-PU.1 complex. J Interferon Cytokine Res. 2005;25:770-9.

60. McAdam E, Haboubi HN, Forrester G, Eltahir Z, Spencer-Harty S, Davies C, et al. Inducible nitric oxide synthase (iNOS) and nitric oxide (NO) are important mediators of reflux-induced cell signalling in esophageal cells. Carcinogenesis. 2012:33:2035-43.

61. Mizel SB, Honko AN, Moors MA, Smith PS, West AP. Induction of macrophage nitric oxide production by Gram-negative flagellin involves signaling via heteromeric Toll-like receptor 5/Toll-like receptor 4 complexes. J Immunol. 2003:170:6217-23.

62. Gao J, Morrison DC, Parmely TJ, Russell SW, Murphy WJ. An interferongamma-activated site (GAS) is necessary for full expression of the mouse iNOS gene in response to interferon-gamma and lipopolysaccharide. J Bio Chem. 1997;272:1226-30.

63. Ganster RW, Taylor BS, Shao L, Geller DA. Complex regulation of human inducible nitric oxide synthase gene transcription by Stat 1 and NF-kappa B. Proc Natl Acad Sci U S A. 2001:98:8638-43.

\section{Submit your next manuscript to BioMed Central and take full advantage of:}

- Convenient online submission

- Thorough peer review

- No space constraints or color figure charges

- Immediate publication on acceptance

- Inclusion in PubMed, CAS, Scopus and Google Scholar

- Research which is freely available for redistribution 